\title{
CORRELAÇÕES FENOTÍPICAS, GENÉTICAS E AMBIENTAIS ENTRE DESCRITORES MORFOLÓGICOS E QUÍMICOS EM FRUTOS DE CUBIU (Solanum sessiliflorum DUNAL) DAAMAZÔNIA ${ }^{1}$
}

\author{
Danilo Fernandes da SILVA FILHO², Jerusa Souza de ANDRADE, Charles \\ Roland CLEMENT ${ }^{2}$, Francisco Manoares MACHADO ${ }^{2}$, Hiroshi NODA ${ }^{2}$
}

RESUMO - O cubiu (Solanum sessiliflorum Dunal) é uma hortaliça da Amazônia, domesticada pelos índios, que pode produzir até $100 \mathrm{t} / \mathrm{ha}$ de frutos ricos em sais minerais e vitaminas. Os frutos são utilizados pelas populações tradicionais da região nas formas de sucos, sorvetes, doces e molhos para carnes bovina, de frango e de peixes. Treze caracteres morfológicos e químicos dos frutos de 24 etnovariedades da Amazônia brasileira, peruana e colombiana foram utilizadas para estimar os coeficientes de correlações fenotipica $\left(r_{f}\right)$, genética $\left(r_{g}\right)$ e de ambiente $\left(\mathrm{r}_{\mathrm{a}}\right)$ entre pares de caracteres. Na maioria dos casos, as correlações genéticas apresentaram valores superiores aos das fenotípicas e de ambientes, indicando que o ambiente teve pouca influência. Entre os caracteres morfológicos, as dimensões dos frutos são estreitamente relacionadas com o teor de umidade. Não foram observadas correlações entre caracteres morfológicos e químicos que pudessem ser úteis ao melhoramento do cubiu. Entre os caracteres químicos, as correlaçōes entre brix e acidez e açúcares redutores e açúcares totais foram altas e positivas $\left(r_{g}=0,62\right.$ e $r_{g}=$ $0,83)$, respectivamente. Entre vários caracteres quimicos será difícil praticar seleção simultânea sem perda de genótipos.

Palavras-chave: Solanaceae, hortaliça amazônica, etnovariedades, genótipos, melhoramento genético.

Phenotypic, Genetic and Environmental Correlations between Morphological and Chemical Descriptors in Fruits of Cubiu (Solanum sessiliflorum Dunal) in Amazonia

ABSTRACT - The cubiu (Solanum sessiliflorum Dunal) is a fruiting shrub domesticated by indians in Amazonia, and produces 40 to $100 \mathrm{t} / \mathrm{ha}$ of fruit rich in minerals and vitamins. The fruits are traditionally used for juices, ice-creams, sweets and in sauces for meat, chicken and fish. Thirteen chemical and morphological characters of 24 etnovarieties of cubiu from Brazilian, Peruvian and Colombian Amazonia were used to estimate the coefficients of phenotypic $\left(\mathrm{r}_{\mathrm{p}}\right)$, genetic $\left(r_{g}\right)$ and environmental $\left(r_{c}\right)$ correlation between pairs of characters. In most cases, the genetic correlations were higher than the phenotypic and environmental correlations, indicating that the environment had less influence. Among the morphological characters, fruit dimensions were closely correlated with moisture. There were no correlations between morphological and chemical characters that could be useful in cubiu improvement. Among the chemical characters, the correlations between brix and acidity and reducing sugars and total sugars were high and positive ( $r_{g}=0,62$ and $r_{g}=0,83$, respectively). Thus, it will be difficult to simultaneously select for these without losing genotypes.

Key-Words: Orinoco apple, Solanaceae, Amazonian fruit, ethnovarieties, genotypes, genetic improvement.

\section{INTRODUÇÃO}

O cubiu (Solanum sessiliflorum Dunal), é conhecido nos paises de lingua espanhola como "tupiro", "topiro", "cocona" e nos países de língua inglêsa como "orinoco apple" e "peach tomato". É uma hortaliça da familia Solanaceae, nativa da América Tropical, com provável origem na

\footnotetext{
Pesquisa financiada com recursos do PPI 4-3360 MCT/INPA

2 Pesquisadores do Instituto Nacional de Pesquisas da Amazônia - INPA Cx. P. 478, 69011-970 Manaus, Amazonas, Brasil.
}

ACTA AMAZONICA 29(4): 503-511. 1999. 
bacia amazônica ou nas vertentes orientais dos Andes peruano, colombiano e equatoriano (Wahlen et al., 1981). O seu processo inicial de domesticação foi feito pelos índios da Amazônia Ocidental (Schultes, 1984).

Esta espécie está adaptada tanto a solos ácidos de baixa fertilidade, quanto a solos neutros e alcalinos de boa fertilidade, com textura desde argilosa a arenosa, situados desde o nível do mar, até 1200 metros de altitude. Cresce bem em zonas com temperaturas médias entre 18 e $35^{\circ} \mathrm{C}$, precipitação pluviométrica de 1500 a $4500 \mathrm{~mm}$ ao ano e a umidade relativa do ar superior a $85 \%$ (Silva Filho et al., 1993).

A polpa é a parte comestivel do fruto. A sua composição quimica apresenta teores de fibras, proteinas, sais minerais e vitaminas que podem ser utilizados como alimento, medicamento e cosmético. Como alimento, face a sua relação Brix/ Acidez considerada baixa $(3,4$ a 6,0$)$, é consumido "in natura", como tira gosto de bebidas alcoólicas ou nas formas de suco, geléias, doces, compotas e em molhos para carnes bovina, de frango e peixes (Silva Filho et al., 1993; Andrade, 1997). Como medicamento tradicional, as folhas maceradas servem para cicatrizar ferimentos provocados por picadas de aranhas e para evitar formação de bolhas em casos de queimaduras. $\mathrm{O}$ suco é recomendado para o controle dos niveis elevados de colesterol, ácido úrico e glicose no sangue, para curar coceiras na epiderme externa e eliminar piolhos que parasitam o homem (Salick, 1989). Como cosmético é usado para limpar e dar brilho a cabelos ressecados (Silva Filho et al., 1997).

O cubiu produz precocemente (aos seis a sete meses de vida). Dependendo do material genético cultivado sua produção de frutos varia de 40 a 100 toneladas por hectare, oferecendo a possibilidade de se programar os plantios para obter colheita o ano inteiro, permitindo o fornecimento de matéria prima constante para a agroindústria (Silva Filho \& Machado, 1997).

A análise de correlação entre caracteres é importante no melhoramento de plantas. Ela possibilita a seleção indireta do caráter desejado, principalmente quando os caracteres envolvidos possuem herança complexa e estão correlacionados a um outro facilmente identificável (Falconer, 1987). Por isso, o conhecimento da associação entre caracteres e as consequências causadas pela mudança simultânea de dois caracteres quaisquer podem resultar em maior eficiência na seleção dos caracteres que se pretende melhorar, ganhando tempo e economizando trabalho, em comparação à seleção isolada para determinado caráter (Amaral Júnior et al., 1997).

Silva Filho et al. (1997, 1998) observaram que entre caracteres da parte vegetativa da planta (diâmetro transversal do caule, altura da planta e área da folha) somente a altura da planta influencia na produção de frutos. Entre onze caracteres estudados, a espessura da polpa e o número de frutos são os que mais se 
correlacionam positivamente com outros caracteres de importância agronômica. Entretanto, não existe estudos sobre as correlações entre caracteres morfológicos e componentes químicos dos frutos. Este trabalho teve o objetivo de avaliar a magnitude das associações entre caracteres morfológicos e componentes químicos do cubiu, para fins de seleção de genótipos que possam contribuir com 0 melhoramento genético da espécie.

\section{MATERIAL E MÉTODOS}

Vinte e quatro etnovariedades (populações de cubiu mantidas "in situ" por índios e caboclos da Amazônia) procedentes de diferentes partes da Amazônia brasileira, peruana e colombiana (Fig. 1) da coleção de germoplasma do Instituto Nacional de Pesquisas da Amazônia (INPA) foram avaliadas.

O experimento de campo foi realizado na Estação Experimental do Ariaú, localizada no municipio de Iranduba, estado do Amazonas, margem esquerda à jusante do rio Solimões, distando-se a $12 \mathrm{~km}$ da Rodovia que liga Cacau Pirera a Manacapuru ( $03^{\circ} 14^{\prime} 22^{\prime \prime}$ S e $60^{\circ} 13^{\prime}$ 50 " W), no periodo de julho de 1995 a abril de 1996.. O solo é do tipo Gley Pouco Húmico, de boa fertilidade. O clima é do tipo tropical quente úmido classificado no esquema de Köppen como "Ami". A temperatura média anual é de $27,7^{\circ} \mathrm{C}$, com $2461 \mathrm{~mm}$ de chuva, ocorrendo $80 \%$ da precipitação no periodo de outubro à maio (EMBRAPA, 1982).

O delineamento experimental foi o de blocos inteiramente casualizados com 24 tratamentos (etnovariedades) e dez repetições representadas por 10 plantas cultivadas sem adubação num espaçamento de $1,5 \times 1,5 \mathrm{~m}$. As análises de variâncias e as estimativas dos coeficientes de correlações fenotípicas $\left(r_{f}\right)$, genética $\left(r_{g}\right)$ e ambiental $\left(r_{a}\right)$ foram calculadas de acordo com a metodologia adotada por Falconer (1987), utilizando o programa GENES (Cruz, 1994).

A colheita dos frutos maduros (apresentando a coloração amarela) foi realizada no periodo de janeiro a abril de 1996. Os seguintes caracteres foram avaliados: largura do fruto - Larg; comprimento longitudinal do fruto Comp; relação comprimento/largura do fruto - $\mathrm{Rcl}$; teor de umidade dos frutos - Umi; $\mathrm{pH}$ do fruto $-\mathrm{pH}$; acidez titulável - At; teor de sólidos solúveis -Brix; relação Brix/At - Rba; ácido ascórbico - Aasc; açúcares redutores açr, açúcares não redutores - açnr; açúcares totais - açt; compostos fenólicos - Feno.

As dimensões foram obtidas de dez frutos de cada planta das 24 etnovariedades. As análises químicas dos frutos foram realizadas na Coordenação de Pesquisas em Tecnologia de Alimentos do INPA, em Manaus, em três frutos de cada planta. A umidade dos frutos foi determinada em estufa com circulação de ar a 65 ${ }^{\circ} \mathrm{C}$. Para a análise dos outros caracteres químicos os frutos foram triturados em liqüidificador, formando uma pasta homogênea, e analisados em três repetições. $\mathrm{O}$ pH, acidez titulável, sólidos 


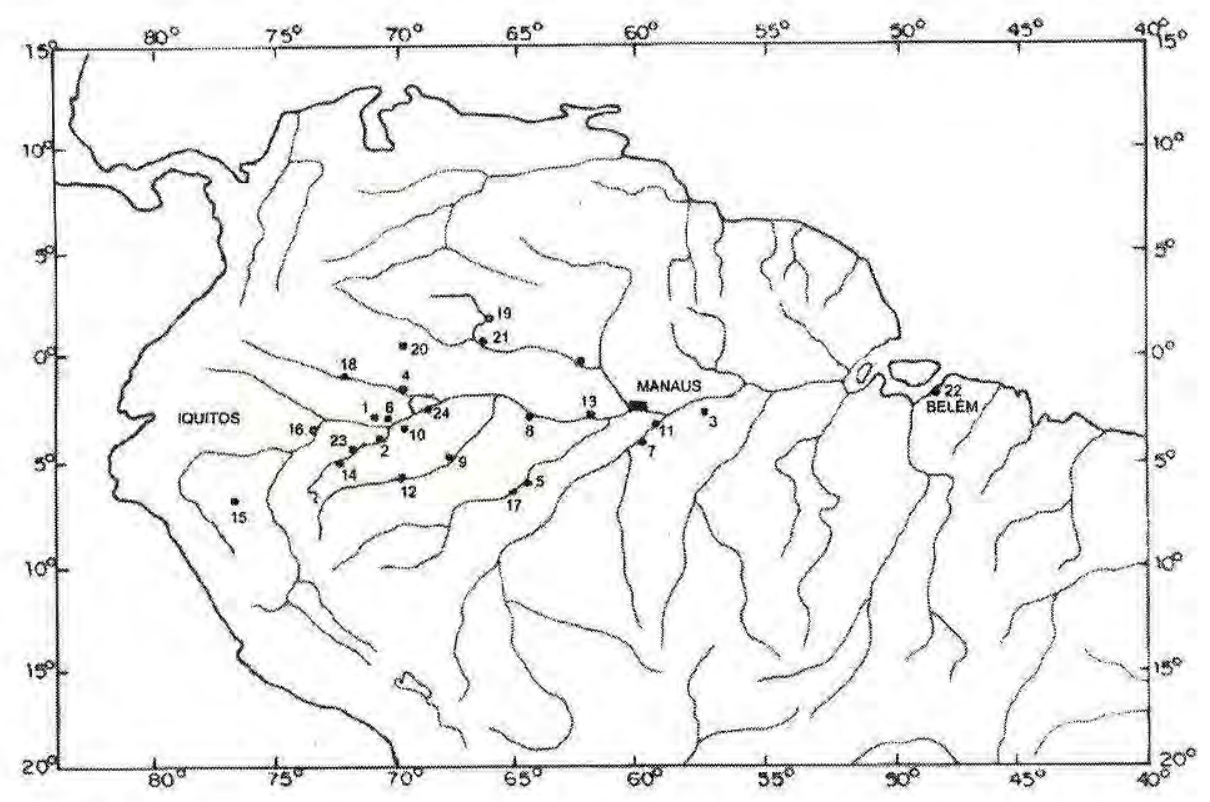

Figura 1: Origem e localização geográfica de 24 etnovariedades de cubiu (S. sessiliflorum) avaliadas em solo de várzea do Rio Solimões no município de Iranduba, AM em 1995/96. 1. Arara; 2. Ataláia do Norte; 3. Ponta Alegre; 4. Ipiranga; 5. Canutama; 6. Umariaçu; 7. Borba; 8. Tefé; 9. Carauari; 10. Benjamin Constant; 11. Nova Olinda; 12. Eirunepé; 13. Coari; 14. Estirão do Equador; 15. Tarapoto; 16. Iquitos; 17. Lábrea; 18. Putumayo; 19. Cucui; 20. Vila Bitencourt; 21. São Gabriel da Cachoeira; 22. Belém; 23. Mayuruna e 24. São Paulo de Olivença.

solúveis e ácido ascórbico (titulação com 2,6-diclorofenolindofenol), seguiram a metodologia de Ranganna (1986). Os açúcares foram extraidos com água $\mathrm{e}$ quantificados antes (redutores) e após a hidrólise ácida (totais) pelo método de Somogy Nelson (Southgate, 1973). A extração dos compostos fenólicos foi feita com metanol $50 \%$, seguindo as recomendações de Goldstein e Swain (1963), e o doseamento pelo método de Folin-Denis (Schanderl, 1970).

\section{RESULTADOS E DISCUSSÃO}

As análises de variância detectaram diferenças significativas entre as etnovariedades para todos os caracteres exceto para relação comprimento/largura do fruto e os açúcares não redutores. Entretanto, a variação fenotípica na maior parte dos caracteres físicos e da composição química dos frutos (Tab. 1) torna possivel a seleção de tipos diferentes para atender o mercado consumidor. Sob o ponto de vista de comercialização, seria conveniente direcionar a seleção de frutos para os formatos redondos, levemente achatado e cordiforme. Frutos com essas características além de apresentarem um atraente aspecto visual, se acomodam melhor nas caixas de transporte e podem ser despolpados manual ou mecanicamente. 
Tabela 1: Variação fenotipica nas dimensões $(n=10)$ e na composição quimica dos frutos de cubiu $(n=3)$.

\begin{tabular}{|c|c|c|c|c|}
\hline Caráter & Média & Desvio Padrăo & Minima & Máxima \\
\hline Comprimento $(\mathrm{cm})$ & 5.70 & 1,15 & 3.95 & 7.83 \\
\hline Largurra $(\mathrm{cm})$ & 5,82 & 1,20 & 4.26 & 8,49 \\
\hline Relação L/C & 1,00 & 0.26 & 0.78 & 1.64 \\
\hline Peso (g) & 114,60 & 63,50 & 47,66 & 292,14 \\
\hline Umidade $(g / 100 \mathrm{~g})$ & 89,85 & 1.45 & 86,7 & 92,77 \\
\hline $\mathrm{pH}$ & 3,39 & 0,11 & 3,23 & 3,70 \\
\hline Acidez $(g / 100 g)$ & 1.47 & 0,22 & 1.04 & 2.00 \\
\hline 'B rix & 6,80 & 0.84 & 5,00 & 8.20 \\
\hline Brix/Acidez & 4.69 & 0.62 & 3,34 & 6,04 \\
\hline Açúcares redutores $(g / 100 g)$ & 2,75 & 0,74 & 1,45 & 4,44 \\
\hline Açúcares não redutores $(\mathrm{g} / 100 \mathrm{~g})$ & 0,69 & 0.40 & 0,04 & 1,84 \\
\hline Açúcares Totais $(\mathrm{g} / 100 \mathrm{~g})$ & 3,47 & 0,71 & 2,06 & 5,00 \\
\hline Fenólicos (mg/100g) & 12,24 & 2,59 & 5,62 & 14.87 \\
\hline Ácido Ascórbico (mg/100g) & 9,85 & 1,82 & 7,68 & 13.87 \\
\hline
\end{tabular}

Para a maioria dos pares de caracteres estudados (Tab. 2), as correlações genéticas apresentaram valores superiores às fenotípicas e de ambiente, indicando que o ambiente teve menor influência que o genótipo. Entretanto, em $52 \%$ das associações houve diferenças de sinais entre as correlações genéticas e de ambiente, $o$ que demonstra como diferentes mecanismos fisiológicos podem causar variação (Falconer, 1987).

Os caracteres largura, comprimento e peso dos frutos mantêm uma estreita correlação com o teor de umidade. Como poder-se-ia esperar o peso do fruto mantém correlação elevada com a largura $\left(r_{\mathrm{g}}=0,95\right)$ e o comprimento dos frutos $\left(\mathrm{r}_{\mathrm{g}}=0,65\right)$. $\mathrm{O}$ comprimento e a largura do fruto não apresentam correlações marcantes com caracteres quimicos que possam ser utilizadas no melhoramento do cubiu.
Já que o melhorista pratica seleção simultânea para vários caracteres baseando-se no sinal e na magnitude da correlação genética, neste experimento, mais de $50 \%$ dos sinais dos coeficientes de correlação genética dos elementos químicos é negativo. Por isso, será difícil, no material avaliado, combiná-los adequadamente, sem a perda de outros caracteres com os quais estejam relacionados.

O caráter compostos fenólicos, embora com baixos valores, foi o que mais apresentou correlações genéticas positivas com outros caracteres químicos e morfológicos dos frutos. Isto é muito importante, porque essas substâncias provenientes do metabolismo secundária dos vegetais, interferem na maturação, sabor, e aroma dos frutos, e conferem às plantas resistência natural a ataques de 
Tabela 2. Estimativa dos coeficientes de Correlação Fenotípica $\left(r_{f}\right)$, Genética $\left(r_{g}\right)$ e Ambiental $\left(\mathrm{r}_{\mathrm{a}}\right)$ entre caracteres morfológicos e químicos em frutos de cubiu. Manaus, 1998.

\begin{tabular}{|c|c|c|c|c|c|c|c|c|c|c|c|c|c|}
\hline $\mathbf{r}$ & $\mathrm{pH}$ & B rix & Acd & Peso & Comp & Larg & $\mathrm{Rcl}$ & Rba & Açrr & Açnr & Açut & Feno & Acas \\
\hline$F$ & 0,165 & $-0,327$ & $-0,644$ & 0,538 & 0,665 & 0,489 & 0,043 & 0,408 & 0,074 & $-0,190$ & $-0,079$ & 0,302 & $-0,069$ \\
\hline UmiG & 0,169 & $-0,338$ & $-0,680$ & 0,567 & 0,710 & 0,519 & 0,168 & 0,437 & 0,071 & $-0,202$ & $-0,085$ & 0,311 & $-0,069$ \\
\hline A & 0,065 & 0,010 & $-0,129$ & 0,043 & $-0,085$ & $-0,026$ & $-0,127$ & $-0,127$ & $-0,018$ & $-0,192$ & 0,008 & 0,030 & $-0,081$ \\
\hline$F$ & & 0,175 & $-0,303$ & 0,241 & $-0,054$ & 0,374 & $-0,190$ & 0,633 & $-0,503$ & 0,204 & $-0,415$ & 0,252 & 0,269 \\
\hline pH G & & 0,178 & $-0,314$ & 0,241 & $-0,066$ & 0,383 & $-0,455$ & 0,660 & $-0,515$ & 0,217 & $-0,431$ & 0,254 & 0,295 \\
\hline A & & 0,119 & $-0,108$ & 0,242 & 0,232 & 0,185 & 0,010 & 0,134 & 0,066 & $-0,063$ & 0,001 & 0,192 & 0,008 \\
\hline $\mathbf{F}$ & & & 0,595 & $-0,386$ & $-0,445$ & $-0,321$ & 0,235 & 0,208 & $-0,612$ & 0,268 & $-0,467$ & $-0,404$ & $-0,018$ \\
\hline Brix G & & & 0,624 & $-0,398$ & $-0,459$ & $-0,329$ & 0,549 & 0,218 & $-0,625$ & 0,278 & $-0,482$ & $-0,489$ & $-0,019$ \\
\hline A & & & $-0,129$ & $-0,048$ & $-0,047$ & $-0,153$ & 0,018 & $-0,013$ & 0,100 & $-0,005$ & 0,058 & 0,725 & $-0,007$ \\
\hline$F$ & & & & $-0,621$ & $-0,592$ & $-0,573$ & 0,025 & $-0,602$ & $-0,156$ & 0,115 & $-0,073$ & $-0,349$ & $-0,157$ \\
\hline Acd G & & & & $-0,634$ & $-0,609$ & $-0,608$ & 0,053 & $-0,600$ & $-0,170$ & 0,120 & $-0,077$ & $-0,361$ & $-0,197$ \\
\hline A & & & & $-0,430$ & $-0,363$ & $-0,082$ & 0,016 & $-0,618$ & 0,170 & 0,054 & $-0,005$ & $-0,191$ & 0,158 \\
\hline$F$ & & & & & 0,610 & 0,932 & $-0,109$ & 0,315 & 0,031 & $-0,171$ & $-0,086$ & 0,338 & $-0,047$ \\
\hline PesoG & & & & & 0,605 & 0,946 & $-0,279$ & 0,337 & 0,033 & $-0,183$ & $-0,091$ & 0,348 & $-0,048$ \\
\hline A & & & & & 0,691 & 0,689 & 0,033 & $-0,006$ & $-0,025$ & 0,009 & 0,010 & 0,062 & $-0,060$ \\
\hline $\mathbf{F}$ & & & & & & 0,412 & 0,299 & 0,219 & 0,347 & $-0,253$ & 0,186 & 0,371 & $-0,125$ \\
\hline CampG & & & & & & 0,414 & 0,655 & 0,227 & 0,363 & $-0,271$ & 0,199 & 0,383 & $-0,146$ \\
\hline A & & & & & & 0,384 & 0,125 & 0,105 & $-0,143$ & 0,010 & $-0,051$ & $-0,012$ & 0,056 \\
\hline $\mathbf{F}$ & & & & & & & $-0,194$ & 0,374 & $-0,066$ & $-0,039$ & $-0,107$ & 0,293 & $-0,068$ \\
\hline Larg G & & & & & & & $-0,452$ & 0,393 & $-0,069$ & $-0,040$ & $-0,113$ & 0,302 & $-0,077$ \\
\hline A & & & & & & & $-0,028$ & 0,089 & $-0,002$ & $-0,026$ & 0,007 & $-0,037$ & 0,005 \\
\hline $\mathbf{F}$ & & & & & & & & 0,113 & 0,136 & 0,186 & 0,239 & $-0,035$ & $-0,246$ \\
\hline RcIG & & & & & & & & 0,279 & 0,287 & 0,458 & 0,540 & $-0,085$ & $-0,996$ \\
\hline A & & & & & & & & $-0,009$ & 0,120 & $-0,015$ & 0,069 & 0,016 & 0,408 \\
\hline$F$ & & & & & & & & & $-0,413$ & 0,164 & $-0,343$ & 0,051 & 0,141 \\
\hline Rba G & & & & & & & & & $-0,426$ & 0,183 & $-0,363$ & 0,053 & 0,167 \\
\hline A & & & & & & & & & $-0,194$ & $-0,088$ & $-0,412$ & 0,059 & $-0,071$ \\
\hline $\mathbf{F}$ & & & & & & & & & & $-0,322$ & 0,834 & 0,128 & $-0,409$ \\
\hline AçurG & & & & & & & & & & $-0,343$ & 0,845 & 0,129 & $-0,449$ \\
\hline A & & & & & & & & & & 0,189 & 0,584 & 0,042 & 0,009 \\
\hline$F$ & & & & & & & & & & & 0,245 & 0,070 & 0,236 \\
\hline AçnrG & & & & & & & & & & & 0,213 & 0,077 & 0,269 \\
\hline A & & & & & & & & & & & 0,798 & $-0,294$ & $-0,026$ \\
\hline$F$ & & & & & & & & & & & & 0,166 & $-0,240$ \\
\hline AçutG & & & & & & & & & & & & 0,172 & $-0,289$ \\
\hline A & & & & & & & & & & & & $-0,162$ & $-0,014$ \\
\hline$F$ & & & & & & & & & & & & & $-0,069$ \\
\hline FenoG & & & & & & & & & & & & & $-0,075$ \\
\hline A & & & & & & & & & & & & & $-0,048$ \\
\hline
\end{tabular}

$\mathrm{r}=$ coeficiente de correlação, $\mathrm{F}=$ fenotipica, $\mathrm{G}=$ genćtica, $\mathrm{A}=$ ambiental, Umi = umidade, $\mathrm{pH}=$ acidez titulável, Brix $=$ teor de sólidos solúveis. Peso $=$ peso do fruto, Comp $=$ comprimento longitudinal do fruto, Larg = Largura do fruto, Rcl = relaçåo entre comprimento e largura do fruto, Rba = relaçăo entre Brix c acidez, Açur = açúcares redutores, Açnr = açúcares năo redutores, Açut = açúcares totais, Feno = fenólicos. 
agentes patogênicos tais como vírus, fungos, e bactérias (Deshpande et al., 1984). Com isso, abrem-se oportunidades para a criação de outras linhas de pesquisas voltadas para o melhoramento do cubiu.

O ácido ascórbico foi aquele que mais apresentou correlação genética negativa com todos os caracteres estudados. É possivel que, em gerações segregantes, as etnovariedades com teores de ácido ascórbico selecionados possam ser combinados com outros caracteres desejados pelo melhorista. A possibilidade pode ser esperada, porque um conjunto gênico com ação pleiotrópica faz com que os blocos gênicos variem e promovam a alteração das associações nas populações derivadas (Cruz \& Regazzi, 1994).

Uma correlação positiva muito importante foi observada entre o teor de sólidos solúveis (Brix) e a acidez titulável $\left(\mathrm{r}_{\mathrm{g}}=0,62\right)$. Isto é importante por duas razões: 1) o Brix é uma característica que em níveis adequados, determina a utilização da fruta tanto para o seu consumo "in natura", quanto para o seu aproveitamento industrial (Chan Júnior \& Kwok, 1976); 2) a acidez titulável é um parâmetro básico para a classificação da fruta pelo sabor. Já que o Brix e o teor de ácido citrico das etnovariedades de cubiu variam em torno de 6,0 a 8,2 e 1,1 a $2,0 \%$, respectivamente, com a coleção de germoplasma do INPA será possivel buscar as combinações de genótipos que permitam melhorar o sabor dos frutos.
$\mathrm{Na}$ composição química dos frutos em geral, os açúcares têm um papel importante na sua aceitação como matéria-prima destinada ao processamento, porque determina a qualidade do produto elaborado (Mowlah \& Itoo, 1982). Como esperado, tanto os açúcares redutores quanto os não redutores se relacionam com o teor de açúcares totais. Entretanto a relação mais estreita acontece entre os caracteres açúcares totais e açúcares não redutores $\left(\mathrm{r}_{\mathrm{g}}=0,85\right)$. Este resultado registra uma tendência que ocorre entre componentes químicos de outras espécies, tais como o tomate e a goiaba (Czyhninciw, 1969; Ledo et al., 1997).

\section{CONCLUSÕES}

Entre os caracteres morfológicos as dimensões dos frutos são estreitamente relacionadas com o teor de umidade. Não foram observadas correlações entre caracteres morfológicos e químicos que pudessem ser úteis no melhoramento do cubiu.

O caráter compostos fenólicos, embora com baixos coeficientes de correlações genéticas, foi o que mais se relacionou com outros caracteres. $\mathrm{O}$ caráter ácido ascórbico foi o que mais se associou negativamente com outros caracteres. Entre os caracteres químicos, as correlações entre Brix e acidez e açúcares redutores e açúcares totais foram altas e positivas $\left(r_{\mathrm{g}}=0,62\right.$ e $r_{g}=0,83$ ), respectivamente. Presume-se que será difícil praticar seleção simultânea entre os caracteres quimicos sem a perda de genótipos. 


\section{Bibliografia citada}

Amaral Junior, A.T.; Casali,V.W.D.; Cruz, C.D.; Finger, F.L. 1997. Correlações simples e canônicas entre caracteres morfológicos, agronômicos e de qualidade em frutos de tomateiro. Horticultura Brasileira, 15(1): 49-52.

Andrade, J.S.; Rocha, I.M.A.; Silva Filho, D.F. 1997. Características e composição química dos frutos de populações naturais de cubiu (Solanum sessiliflorum Dunal) avaliadas na Amazônia Central. In: $I$ Encontro Norte Nordeste da SBCTA. Fortaleza, CE, p. 26.

Chan Júnior, H.T,; Kwok, S.C.M. 1976. Identification of sugars in some tropical fruit products. Journal of Food Science, 40(2): 419-430.

Czyhrinciw, N. 1969. Tropical fruit technology. Advances in Food Research, 17: 153-214.

Cruz,C.D.; Regazzi, A.J. 1994. Modelos biométricos aplicados ao melhoramento genético. Viçosa: Imprensa Universitária, 394 p.

Deshpande, S.S.; Sathe, S.K.; Salunkhe. D.K. 1984. Chemistry and safety of plant polyphenolis. In: Friedman, M. (ed) $\mathrm{Nu}$ tritional and Toxicological Aspects of Food. Plenum: New York. P. 457-495.

EMBRAPA, Boletim agrometeorológico. Manaus. 1982. EMBRAPA/UEPAE, 22 p.

Falconer, D.S. 1987. Introduction to quantitative genetic. 2 ed. London: Longman, 340 p.

Goldstein, J.L.; Swain, T. 1963. Changes in tannins in ripening fruits. Phytochemistry, 2: $371-383$.

Ledo, A.S.; Silva, S.O.; Azevedo, F.F. 1997. Avaliação preliminar de genótipos de banana (Musa spp.) em Rio BrancoAcre. Revista Brasileira de Fruticultura, Cruz das Almas, 19(1): 51-56.

Mowlah, G.; Itoo, S. 1982. Guava (Psidium guajava L.) sugar component and related enzymes at stages fruit development and ripening. Jour- nal of Japanese Society of Food Science and Tecnology, 29(8): 472-476.

Ranganna, S. 1986. Analysis and quality control for fruit and vegetables products. New Delhi: Tata Mc Graw-Hill Publishing, p, 1-118.

Salick, J. 1989. Cocona (Solanum sessiliflorum Dunal), an. Overview of productions and breeding potentials. In: International Symposium on new crops for food and industry. Southampton: University Southampton, p. 125-129.

Schanderl, S.H. 1970. Tannins and related phenolics. In: Josly, M. A. (ed.) Methods in food analysis. New York, Academic Press, p 701-725.

Schultes, R.E. 1984. Amazonian cultigens and their northward migrations in preColombian times. In: Schultes, R.E. Pre-historic plant migrations. Cambridge: Haward University Press, p. 19-38.

Silva Filho, D.F.; Noda, H.; Clement, C.R. 1993. Genetic variability of economic characters in 30 accessions of cubiu (Solanum sessiliflorum Dunal) evalueted in Central Amazonia. Revista Brasileira de Genética, 16; 409-417.

Silva Filho, D.F.; Anunciação Filho, C.J.; Noda, H.; Reis, O.V. 1997. Seleção de caracteres correlacionados em cubiu (Solanum sessiliflorum Dunal) empregando a análise de trilha. Acta Amazonica, 27(4): 229-240.

Silva Filho, D.F.; Machado, F.M. 1997. Cubiu (Solanum sessiliflorum Dunal). In: Cardoso, M.O. (ed). Hortaliças não convencionais da Amazônia. Brasília: EMBRAPA-SPI. Manaus: EMBRAPACPAA, p. 97-104.

Silva Filho, D.F.; Anunciação Filho, C.J.; Noda, H.; Reis, O.V. 1998. Estimativas de herdabilidades e correlações entre caracteres em populações de cubiu (Solanum sessiliflorum Dunal) da Amazônia. Revista Brasileira de Fruticultura, 20(1): 7-14. 
Southgate, D.A.T. 1973. Determination of food carbohydrates. London, Aplied Science Publishing, $178 \mathrm{p}$.

Wahlen, M.D.; Costich, D.E.; Heiser, C.B. 1981. Taxonomy of Solanum section Lasiocarpa. Gentes Herbarum, 12(2): 4-129.

Aceito para publicação em 18/08/1999 